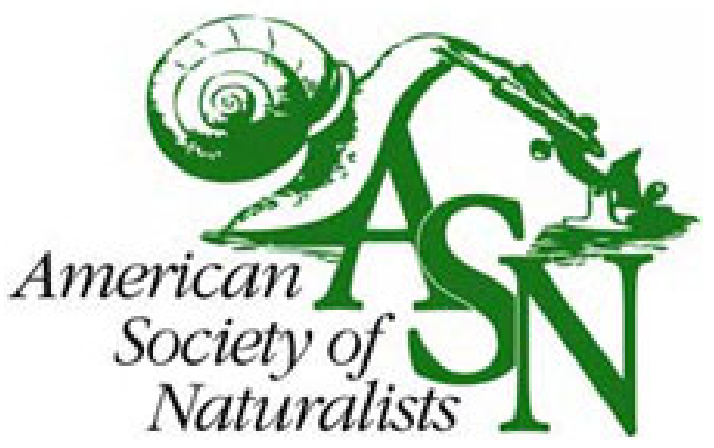

The University of Chicago

Selection through Female Fitness Helps to Explain the Maintenance of Male Flowers. Author(s): Mario Vallejo-Marín and Mark D. Rausher

Reviewed work(s):

Source: The American Naturalist, Vol. 169, No. 5 (May 2007), pp. 563-568

Published by: The University of Chicago Press for The American Society of Naturalists

Stable URL: http://www.jstor.org/stable/10.1086/513112

Accessed: 12/07/2012 09:42

Your use of the JSTOR archive indicates your acceptance of the Terms \& Conditions of Use, available at http://www.jstor.org/page/info/about/policies/terms.jsp

JSTOR is a not-for-profit service that helps scholars, researchers, and students discover, use, and build upon a wide range of content in a trusted digital archive. We use information technology and tools to increase productivity and facilitate new forms of scholarship. For more information about JSTOR, please contact support@jstor.org. 


\section{Selection through Female Fitness Helps to Explain the Maintenance of Male Flowers}

\author{
Mario Vallejo-Marín ${ }^{\star}$ and Mark D. Rausher ${ }^{\dagger}$ \\ Biology Department, Duke University, Durham, North Carolina \\ 27708
}

Submitted June 1, 2006; Accepted November 27, 2006;

Electronically published March 7, 2007

\begin{abstract}
Andromonoecy, the production of both male and hermaphrodite flowers in the same individual, is a widespread phenomenon that occurs in approximately 4,000 species distributed in 33 families. Hypotheses for the evolution of andromonoecy suggest that the production of intermediate proportions of staminate flowers may be favored by selection acting through female components of fitness. Here we used the andromonoecious herb Solanum carolinense to determine the pattern of selection on the production of staminate flowers. A multivariate analysis of selection indicates that selection through female fitness favors the production of staminate flowers in at least one population. We conclude that this counterintuitive benefit of staminate flowers on female fitness highlights the importance of considering female components of fitness in the evolution of andromonoecy, a reproductive system usually interpreted as a "male" strategy.
\end{abstract}

Keywords: andromonoecy, multivariate selection, nonfruiting flowers, Solanum carolinense, Solanaceae.

Andromonoecy, the production of both perfect (hermaphrodite) and staminate (male) flowers on the same individual, has evolved multiple times during the history of angiosperms and occurs in approximately 4,000 species across several families (Yampolsky and Yampolsky 1922; Richards 1986; Miller and Diggle 2003). Despite this repeated evolution, we have only a rudimentary understanding of the evolutionary mechanisms that favor the pro-

\footnotetext{
* Corresponding author. Present address: Department of Ecology and Evolutionary Biology, University of Toronto, 25 Willcocks Street, Toronto, Ontario M5S 3B2, Canada; e-mail: mvallejo@botany.utoronto.ca.

† E-mail: mrausher@duke.edu.
}

Am. Nat. 2007. Vol. 169, pp. 563-568. (C) 2007 by The University of Chicago. 0003-0147/2007/16905-41871\$15.00. All rights reserved. duction of staminate flowers (Bertin 1982; Podolsky 1992, 1993; Elle and Meagher 2000).

An obvious potential selective advantage of producing staminate flowers is increased male reproductive success. Empirical support for this advantage, however, is equivocal, in part because few empirical studies have quantified siring success in andromonoecious taxa. On the one hand, Elle and Meagher (2000) found support for this hypothesis by demonstrating that, in some populations of Solanum carolinense, plants that produce higher proportions of staminate flowers also have higher siring success. By contrast, other studies have failed to detect such an advantage (Vallejo-Marín and Rausher 2007 [Solanum carolinense]; Podolsky 1993 [Besleria triflora]).

A second, perhaps counterintuitive, selective advantage of producing staminate flowers may be an increase in seed production. Theoretically, such an advantage may arise via several mechanisms: (1) if resources saved by producing smaller staminate flowers lacking pistils (Ruiz Zapata and Kalin Arroyo 1978; Primack and Lloyd 1980; Bertin 1982; Solomon 1985; Spalik 1991; Emms 1993) are reallocated to seed production, staminate flower production may increase seed set; (2) if seed set is pollinator limited and staminate flowers are more attractive to pollinators than perfect flowers, production of some staminate rather than all perfect flowers may increase visitation to a plant and, thus, seed set of the perfect flowers (Podolsky 1992); (3) even if seed production is resource limited, increased visitation and pollen input achieved through the production of more attractive staminate flowers could increase offspring quality by facilitating enhanced competition among pollen tubes for access to ovules; and (4) if reduced pistils of staminate flowers remove less pollen from pollinators than normal pistils of perfect flowers, then to the extent that pollinators visit staminate flowers before perfect flowers in the same or different inflorescences, more non-self pollen would be available for the stigmas of fruit-producing flowers (e.g., Besleria triflora; Podolsky 1992). To date, there is little evidence for the operation of any of these mechanisms, again because few studies have at- 
tempted to quantify the effects of staminate flower production on seed set.

In another article (Vallejo-Marín and Rausher 2007), we reported that the production of staminate rather than perfect flowers does not detectably increase male fitness in the andromonoecious herb Solanum carolinense. Here we report the results of an experiment designed to determine whether selection on staminate flower production through female function contributes to the persistence of andromonoecy in this species.

\section{Material and Methods}

\section{Study Species}

Horse nettle, Solanum carolinense L. (subgenus Leptostemonum, Solanaceae), is a perennial herb native to the southeastern United States. It reproduces both sexually and clonally through lateral roots. Like other members of the Solanaceae, it displays a gametophytic self-incompatibility system that enforces outcrossing. Individual plants produce two types of flowers: staminate (male) and perfect (hermaphroditic). Flowers are borne in racemes (hereafter inflorescences) on which several flowers typically are open simultaneously (Solomon 1985; 1-39 open flowers per individual, M. Vallejo-Marín, personal observation). Staminate flowers have reduced styles, which do not extend beyond the anthers, and reduced ovaries, and they fail to set fruit even when artificially pollinated (Solomon 1985). Flowers produce no nectar and are buzz-pollinated by large bees.

\section{Seed Collection}

In 2001, a total of 147 fruits were collected from S. carolinense plants growing in an abandoned agricultural field in Orange County, North Carolina. The sampling design was chosen as a trade-off between collecting a large number of fruits and sampling from as many different genets as possible. One fruit per plant was sampled trying to maximize the distance between individuals (3-5 $\mathrm{m}$ apart from each other).

\section{Experimental Procedures}

To generate experimental seeds, we performed a single generation of selection on the plants grown in the greenhouse from the field-collected seeds. The primary purpose of this selection was to increase the range of variation in order to facilitate detection of selection (Conner 2003). Because we expected the production of staminate flowers to have a large environmental component of variance, we used index selection (Falconer and Mackay 1996). Arti- ficial selection was done on the proportion of staminate flowers (PSF; staminate/total flowers) rather than the absolute number of staminate flowers. In this procedure, the parents of the up- or down-selected line consisted of the individuals with the highest (lowest) PSF from each of the 10 maternal families with the highest (lowest) average PSF, while the parents of the control line consisted of the individuals with the median PSF from each of the $10 \mathrm{ma}-$ ternal families with the average PSF closest to the overall mean. Selection was from 412 individuals in 134 maternal families. The average PSF values for the selected individuals of the up-selected, down-selected, and control lines were $0.489,0.021$, and 0.218 , respectively. Within each selected line, we performed a complete diallele cross, except selfs, to obtain 90 full-sib families for each line.

Between July 5 and 7, 2003, we established two experimental populations in an abandoned agricultural field surrounded by woods in Orange County, North Carolina. Each population consisted of 320 individuals planted in a randomized two-block design. Individuals were placed 1 $\mathrm{m}$ apart in a square grid, which is within the range of natural populations' size and density (Elle 1999; Wise 2003; M. Vallejo-Marín, personal observation). The two populations were separated by approximately $40 \mathrm{~m}$ by a large experimental plot of morning glories (Ipomoea spp.).

For reasons unrelated to this report, the two populations differed in the relative frequencies of plants from the different selected lines. In population 1, we randomly picked 55,15 , and 10 full-sib families from the dialleles of the down-selected, control, and up-selected lines, respectively. For population 2, the respective numbers were 10, 15, and 55. Four replicate seeds from each full-sib family were germinated, grown in the greenhouse for 1 month to equalize maternal effects, and then transplanted into the field.

We surveyed the experimental populations during two consecutive flowering seasons, in 2003 and 2004. Because few plants flowered in 2003, we report only the results from 2004. In 2004, to maintain a constant number of flowering ramets per genet between years, all but one ramet per planted seed was prevented from flowering. To estimate the production of staminate and perfect flowers, which typically persist for 3-4 days in the field (Wise 2003; M. Vallejo-Marín, personal observation), we recorded the sex of each open flower every other day. Each flower was marked at the base of the pedicel to avoid counting the same flower twice. We used a digital caliper to measure corolla width, petal length and width, anther length and width, and pistil exsertion from the tip of the anthers, for up to three flowers of each sex in each individual. To determine the relationship between flower production and aboveground growth, we measured the height of the tallest 
Table 1: Variance components and narrow-sense heritability of staminate and perfect flower number in field populations

\begin{tabular}{lccrcc}
\hline Trait & $V_{\mathrm{A}}$ & $V_{\mathrm{E}}$ & \multicolumn{1}{c}{$V_{\mathrm{P}}$} & $h^{2}$ & $t(\mathrm{df}=1,358)$ \\
\hline Staminate flowers & $.168(.047)$ & $.756(.050)$ & .961 & $\mathbf{. 1 8 2}(.046)$ & 3.931 \\
Perfect flowers & $.001(.026)$ & $1.062(.053)$ & 1.064 & $.001(.027)$ & .054 \\
\hline
\end{tabular}

Note: Variance estimates were obtained by fitting an "animal model" to the data using restricted maximum likelihood (Neumaier and Groeneveld 1998). Standard errors are shown in parentheses. The null hypothesis that the true narrow-sense heritability is equal to 0 was tested using a one-tailed $t$-test. $V_{\mathrm{A}}=$ additive genetic variance; $V_{\mathrm{E}}=$ environmental variance; $V_{\mathrm{P}}=$ phenotypic variance. All analyses were done using transformed data. Boldface indicates $P<.0001$.

branch (to the nearest centimeter), and total leaf area (to the nearest $5 \mathrm{~cm}^{2}$ ) at the end of each flowering season.

Our estimate of female fitness was based on total seed production. Fruits were collected as they matured, to minimize fruit loss due to dispersal. Seed number was estimated using Wise's equation, which successfully predicts seed number based on fruit diameter $\left(r^{2}=0.90\right.$; Wise 2003).

\section{Data Analysis}

To assess whether the production of staminate flowers is, at least in part, genetically determined, we estimated its genetic variance and heritability in the field. We used the so-called animal model to estimate genetic components of variance (for reviews on this approach, see Lynch and Walsh 1998; Kruuk 2004). This mixed-effects model explicitly accounts for the pedigree relationships among individuals. In this approach, inbreeding, nonrandom mating, and selection do not bias the variance estimates. Additionally, since the model is fitted through restricted maximum likelihood (REML), this approach does not depend on balanced designs and is relatively insensitive to nonnormality of the data, and the information contained in the data set is used maximally (Shaw 1987; Lynch and Walsh 1998; Kruuk 2004). Analyses were performed using the program REML VCE (ver. 5.1; Neumaier and Groeneveld 1998). The data set used in this analysis included all the field-grown plants that flowered in 2004 plus the 30 greenhouse-grown parental plants. Population (with greenhouse coded as population 3) and block were included as fixed effects.

To estimate the pattern of selection on staminate and perfect flower number, we calculated selection gradients in standard fashion using multivariate regression analysis of fitness on the character(s). We employed standard phenotypic analysis of selection (Lande and Arnold 1983) as well as a genetic analysis of selection based on paternal half-sib family means (Rausher 1992; Stinchcombe et al. 2002).

To allow comparison of selection acting on traits measured in different units and across different environments, all selection differentials and gradients were calculated using traits standardized to a mean of 0 and a variance of 1 (Lande and Arnold 1983). Standardization was done separately for each population. Fitness was relativized to a mean of 1 within each population. Analyses were calculated on the residuals obtained after the effects of block were removed to minimize the effect of environmental differences due to location in the field. The statistical significance of selection differentials and gradients was calculated from a model in which relative fitness was log transformed to improve the normality of the residuals (Stinchcombe 2005). Analyses were done with the statistical program R (R Development Core Team 2005). All models were fitted using the function "glm," and F-tests were calculated by deleting individual terms from the model following the marginality principle using "drop1."

Phenotypic analysis of selection has the advantage, compared to genetic analysis, of being potentially more powerful because of the larger sample size. By contrast, selection differentials and gradients potentially are biased by environmentally induced correlations between fitness and the characters (Rausher 1992). To determine whether environmental correlations biased our estimates of selection using phenotypic values, we used the statistical test suggested by Stinchcombe et al. (2002). This test compares the selection coefficients estimated from genetic values with the analogous regression coefficient of fitness on environmental deviations. If the two estimated coefficients are statistically indistinguishable, then it can be concluded that there is no environmental bias in the phenotypic estimate of selection.

\section{Results \\ Heritability of Traits}

We found significant variation among paternal half-sib families for number of staminate flowers but not for number of perfect flowers (table 1). The corresponding narrowsense heritability estimate for number of staminate flowers is 0.182 . 


\section{Pattern of Selection}

Although we detected no significant genetic variation for number of perfect flowers, in a previous investigation (M. Vallejo-Marín and M. D. Rausher, unpublished data), we found that number of staminate flowers is genetically correlated with number of perfect flowers $\left(r_{\mathrm{G}}=0.576, t=\right.$ 3.737, $\mathrm{df}=28, P<.001)$. Because the latter is a priori expected to be subject to selection, we conducted multivariate selection analyses to separate effects of direct and indirect selection on staminate flower number. Initially, we performed analyses that also included flower size and plant size as possible targets of selection. However, because we did not detect any selection on either flower size or plant size, these characters were dropped from subsequent analyses, and we report only the results of analyses including flower numbers.

Qualitatively, the phenotypic and genetic multivariate selection analyses produce similar results (table 2 ). Moreover, a comparison of phenotypic and genetic selection gradients reveal no evidence of environmentally induced bias in the phenotypic gradients (table 3 ). Consequently, we take the results of the phenotypic analysis as accurate.

As expected, selection for number of perfect flowers is positive for both populations. Additionally, the negative quadratic coefficient for this character in population 2 suggests that selection is stabilizing. More interestingly, the phenotypic analysis reveals evidence for positive directional selection acting directly to increase the number of staminate flowers in population 2 .

\section{Discussion}

Our results indicate that in the andromonoecious herb Solanum carolinense, the production of staminate flowers is genetically variable, as reflected by a significant narrowsense heritability in the field. Given this variation, the question arises as to why genotypes that produce staminate flowers are not eliminated; that is, why does andromonoecy persist in this species?

The directional selection for increased number of staminate flowers detected in population 2 would clearly contribute to the maintenance of andromonoecy in this species. Our failure to detect such selection in population 1 indicates that the pattern of selection on staminate flower number may be sensitive to local environmental conditions and that it may fluctuate over time as well. Without a more extensive characterization of the spatial and temporal patterns of variation in selection on staminate flower number, it is not possible to determine whether net selection, averaged over time and space, favors the persistence of staminate flowers. We note, however, that in neither population was there significant selection favoring a decrease in staminate flower number, which may indicate that such selection is relatively rare compared to selection to increase staminate flower number. Since the two populations differed in the relative frequencies of plants from the different selected lines (see "Material and Methods"), it is also possible that our ability to detect selection was affected by genotypic composition. However, we did not observe a strong difference between populations in the frequency distribution of phenotypic values of the proportion of staminate flowers, and a statistical analysis of the effect of population on this proportion was nonsignificant (data not shown). At the very least, our results indicate that the hypothesis that production of staminate flowers increases female fitness should be taken seriously.

The observed enhancement of seed production is not necessarily the only benefit that may be associated with production of staminate flowers in S. carolinense. Elle and

Table 2: Standardized selection gradients acting on the number of staminate and perfect flowers of phenotypic and genotypic values

\begin{tabular}{lcccr}
\hline & $\beta$ (phenotypic) & $\beta$ (genotypic) & $\gamma$ (phenotypic) & $\gamma$ (genotypic) \\
\hline Population 1: & & & & -.162 \\
$\quad$ Staminate flowers & -.044 & -.152 & -.025 & .262 \\
Perfect flowers & $1.854^{\star * \star}$ & $.800^{\star *}$ & .228 & -.494 \\
$\quad$ Staminate $\times$ perfect flowers & & & -.238 & -.062 \\
Population 2: & & & & -.017 \\
$\quad$ Staminate flowers & $.107^{\star}$ & .103 & $-.086^{\star * \star}$ & -.016 \\
$\quad$ Perfect flowers & $1.251^{\star * *}$ & $.917^{\star * *}$ & .043 & -.133 \\
$\quad$ Staminate $\times$ perfect flowers & & & \\
\hline
\end{tabular}

Note: Both linear $(\beta)$ and quadratic $(\gamma)$ selection gradients are shown. The value of the selection gradients was calculated using relative fitness $(w)$, but statistical significance was estimated using a $\log (w+1)$ transformation to improve normality of the residuals. Coefficients were calculated using standardized traits $\left(\bar{x}=0, \sigma^{2}=1\right)$. All analyses were carried out on the residuals after block effects within populations had been removed.

* $P<.01$.

** $P<.001$.

*** $P<.0001$. 
Table 3: Statistical test for environmental bias in selection estimates

\begin{tabular}{|c|c|c|c|c|c|c|c|c|c|c|}
\hline \multirow[b]{2}{*}{ Trait } & \multicolumn{5}{|c|}{ Directional } & \multicolumn{5}{|c|}{ Quadratic } \\
\hline & $\beta_{X}$ & $\beta_{Y_{i}-X}$ & $F$ & $\mathrm{df}$ & $P$ & $\gamma_{X}$ & $\gamma_{Y_{i}-X}$ & $F$ & $\mathrm{df}$ & $P$ \\
\hline \multicolumn{11}{|l|}{ Population 1: } \\
\hline No. staminate flowers: & -.045 & -.086 & .255 & 97 & .614 & -.093 & .100 & .304 & 91 & .582 \\
\hline No. perfect flowers & .430 & .376 & .444 & 97 & .506 & .030 & -.036 & .012 & 91 & .911 \\
\hline \multicolumn{11}{|l|}{ Staminate $\times$ perfect } \\
\hline flower number & & & & & & -.009 & -.128 & 2.406 & 91 & .124 \\
\hline \multicolumn{11}{|l|}{ Population 2: } \\
\hline No. staminate flowers: & .055 & .056 & .001 & 221 & .975 & -.099 & .006 & .255 & 215 & .613 \\
\hline No. perfect flowers & .386 & .442 & 1.402 & 221 & .237 & -.051 & -.069 & 1.110 & 215 & .293 \\
\hline \multicolumn{11}{|l|}{ Staminate $\times$ perfect } \\
\hline flower number & & & & & & .061 & .070 & 2.633 & 215 & .106 \\
\hline
\end{tabular}

Note: $\beta_{X}$ and $\gamma_{X}$ represent, respectively, the linear and quadratic coefficients of selection on genetic values. $\beta_{Y_{i}-X}$ and $\gamma_{Y_{i}-X}$ are the coefficients corresponding to selection on environmental deviations. The null hypothesis (no difference between selection calculated using genetic or phenotypic values) is rejected if the coefficients obtained using genetic values $(X)$ and environmental deviations $\left(Y_{i}-X\right)$ are statistically different from each other. Significance was tested using an $F$-test as suggested by Stinchcombe et al. (2002). All analyses done on transformed data.

Meagher (2000) reported that plants producing a higher proportion of staminate flowers had higher male fitness even when variation in flower number was statistically controlled for, implying that staminate flowers are more efficient than perfect flowers at exporting pollen. By contrast, Vallejo-Marín and Rausher (2007) failed to find any difference in siring success between perfect and staminate flowers. As with our results on female fitness, these disparate results may indicate that the benefit of increased male fitness is also temporally or spatially variable. It is thus possible that increased male success is the primary benefit of andromonoecy in some populations, while in others it is increased female success.

To our knowledge, only two other investigations have examined the effect of staminate flowers on seed production. Podolsky (1992) showed that in Besleria triflora pollen receipt is increased with the addition of staminate flower: $\rightarrow$ but not with the addition of perfect ones. In contrast, Solomon (1987) concluded that the addition of staminate flowers did not increase fruit set in S. carolinense. Our results, in combination with these studies, suggest that the counterintuitive effect of staminate flowers in increasing female success may often, though not always, contribute to the evolution of andromonoecy.

\section{Acknowledgments}

We thank M. Wise for providing his expertise with horst $\rightarrow$ nettle and for sharing his unpublished data. B. Calhoun and the Duke greenhouse staff patiently tended plants for several years, making this research possible. Many people valiantly contributed with long hours in the field; we especially thank C. Kaiser, C. King, D. Speiser, and I. Vallejo. Critical comments by many regular Pop Bio attendees helped to shape this project. The comments by
C. Kaiser, W. Morris, A. Motten, J. Willis, W. Wilson, and two anonymous reviewers greatly improved previous versions of the manuscript. This work was partially supported by a Consejo Nacional de Ciencia y Teconología (Mexico) graduate fellowship to M.V.-M. and a Dissertation Improvement Grant by the National Science Foundation (DEB-0407838) to M.V.-M. and M.D.R.

\section{Literature Cited}

Bertin, R. I. 1982. The evolution and maintenance of andromonoecy. Evolutionary Theory 6:25-32.

$\rightarrow$ Conner, J. K. 2003. Artificial selection: a powerful tool for ecologists. Ecology 84:1650-1660.

Elle, E. 1999. Sex allocation and reproductive success in the andromonoecious perennial Solanum carolinense (Solanaceae). I. Female success. American Journal of Botany 86:278-286.

Elle, E., and T. R. Meagher. 2000. Sex allocation and reproductive success in the andromonoecious perennial Solanum carolinense (Solanaceae). II. Paternity and functional gender. American Naturalist 156:622-636.

Emms, S. K. 1993. Andromonoecy in Zigadenus paniculatus (Liliaceae): spatial and temporal patterns of sex allocation. American Journal of Botany 80:914-923.

Falconer, D. S., and T. F. C. MacKay. 1996. Introduction to quantitative genetics. Longman, Essex.

$\rightarrow$ Kruuk, L. E. B. 2004. Estimating genetic parameters in natural populations using the "animal model." Philosophical Transactions of the Royal Society B: Biological Sciences 359:873-890.

Lande, R., and S. J. Arnold. 1983. The measurement of selection on correlated characters. Evolution 37:1210-1226.

Lynch, M., and B. Walsh. 1998. Genetics and analysis of quantitative traits. Sinauer, Sunderland, MA.

Miller, J. S., and P. K. Diggle. 2003. Diversification of andromonoecy in Solanum section Lasiocarpa (Solanaceae): the roles of phenotypic plasticity and architecture. American Journal of Botany 90:707715.

Neumaier, A., and E. Groeneveld. 1998. Restricted maximum like- 
lihood estimation of covariances in sparse linear models. Genetics Selection Evolution 30:3-26.

$\rightarrow$ Podolsky, R. D. 1992. Strange floral attractors: pollinator attraction and the evolution of plant sexual systems. Science 258:791-793.

$\rightarrow$. 1993. Evolution of a flower dimorphism: how effective is pollen dispersal by male flowers. Ecology 74:2255-2260.

$\rightarrow$ Primack, R. B., and D. G. Lloyd. 1980. Andromonoecy in the New Zealand montane shrub Manuka, Leptospermum scoparium (Myrtaceae). American Journal of Botany 67:361-368.

R Development Core Team. 2005. R: a language and environment for statistical computing, version 2.1.1. Foundation for Statistica Computing, Vienna.

$\rightarrow$ Rausher, M. D. 1992. The measurement of selection on quantitative traits: biases due to environmental covariances between traits and fitness. Evolution 46:616-626.

Richards, A. J. 1986. Plant breeding systems. Chapman \& Hall, London.

$\rightarrow$ Ruiz Zapata, T., and M. T. Kalin Arroyo. 1978. Plant reproductive ecology of a secondary deciduous tropical forest in Venezuela. Biotropica 10:221-230.

$\rightarrow$ Shaw, R. G. 1987. Maximum likelihood approaches applied to quantitative genetics of natural populations. Evolution 41:812-826.

$\rightarrow$ Solomon, B. P. 1985. Environmentally influenced changes in sex expression in an andromonoecious plant. Ecology 66:1321-1332.
1987. The role of male flowers in Solanum carolinense: pollen donors or pollinator attractors. Evolutionary Trends in Plants 1: 89-93.

Spalik, K. 1991. On evolution of andromonoecy and overproduction of flowers: a resource-allocation model. Biological Journal of the Linnean Society 42:325-336.

Stinchcombe, J. R. 2005. Measuring natural selection on proportional traits: comparisons of three types of selection estimates for resistance and susceptibility to herbivore damage. Evolutionary Ecology 19:363-373.

$\rightarrow$ Stinchcombe, J. R., M. T. Rutter, D. S. Burdick, P. Tiffin, M. D. Rausher, and R. Mauricio. 2002. Testing for environmentally induced bias in phenotypic estimates of natural selection: theory and practice. American Naturalist 160:511-523.

Vallejo-Marín, M., and M. D. Rausher. 2007. The role of male flowers in andromonoecious species: energetic costs in Solanum carolinense L. Evolution 61:404-412.

Wise, M. J. 2003. The ecological genetics of plant resistance to herbivory: evolutionary constraints imposed by a multiple-herbivore community. PhD diss. Duke University, Durham, NC.

Yampolsky, E., and H. Yampolsky. 1922. Distribution of sex forms in the phanerogamic flora. Bibliographia Genetica 3:1-62.

Associate Editor: Elizabeth Elle Editor: Monica A. Geber 